\title{
Development of Enhanced Value, Feature, and Stakeholder Views for a Model- Based Design Approach
}

\section{Dr. William A Kline, Rose-Hulman Institute of Technology}

Bill Kline is Professor of Engineering Management and Associate Dean of Innovation at Rose-Hulman. His teaching and professional interests include systems engineering, quality, manufacturing systems, innovation, and entrepreneurship. As Associate Dean, he directs the Branam Innovation Center which houses campus competition teams, maker club, and projects.

$\mathrm{He}$ is currently an associate with IOI Partners, a consulting venture focused on innovation tools and systems. Prior to joining Rose-Hulman, he was a company co-founder and Chief Operating Officer of Montronix, a company in the global machine monitoring industry.

Bill is a Phi Beta Kappa graduate of Illinois College and a Bronze Tablet graduate of University of Illinois at Urbana Champaign where he received a Ph.D. degree in Mechanical Engineering.

\section{Mr. William D. Schindel, ICTT System Sciences}

William D. Schindel is president of ICTT System Sciences, a systems engineering company, and developer of the Systematica Methodology for model and pattern-based systems engineering. His 40-year engineering career began in mil/aero systems with IBM Federal Systems, Owego, NY, included service as a faculty member of Rose-Hulman Institute of Technology, and founding of three commercial systems-based enterprises. He has consulted on improvement of engineering processes within automotive, medical/health care, manufacturing, telecommunications, aerospace, and consumer products businesses. Schindel earned the BS and MS in Mathematics.

\section{Dr. Ashley Bernal, Rose-Hulman Institute of Technology}

Ashley Bernal is an Assistant Professor of Mechanical Engineering at Rose-Hulman Institute of Technology. She received her PhD from Georgia Institute of Technology in 2011. She was an American Society of Mechanical Engineers (ASME) teaching fellow and Student Teaching Enhancement Partnership (STEP) Fellow. Prior to receiving her PhD, she worked as a subsystems engineer at Boeing on the Joint Unmanned Combat Air Systems (JUCAS) program. Her research areas of interest include piezoelectrics, nanomanufacturing, optical measuring techniques, and intercultural design.

\section{Dr. Mario Simoni, Rose-Hulman Institute of Technology}

Mario Simoni is Department Head and Professor of Electrical and Computer Engineering at Rose-Hulman Institute of Technology. 


\section{Development of Enhanced Value, Feature, and Stakeholder Views for a Model-Based Design Approach}

The increasing complexity of the workplace that engineering students find upon graduation suggests that they must be not only technical problem solvers but also innovators and value creators. The designs and solutions they create must solve technical problems and provide benefit to a variety of interested stakeholders. Students must also adopt a broad view of value and benefit that includes financial, social, and environmental aspects. The challenge for engineering educators becomes how to develop and teach a design approach that educates students in this broader mindset and skillset of technical problem solving plus value creation.

Recent work has proposed a systems-based approach for design that focuses on the underlying set of relationships, and this approach has found application in engineering education from first year to capstone design courses. This approach develops a number of 'views' of models of the system to be designed including stakeholders, features, interactions, and functional views. These views provide the multiple perspectives of the system to be designed that are necessary to describe the value or fitness, structure, general functionality, and detailed behavior of the system. This previous work has been presented at INCOSE and ASEE and will be briefly described in the paper.

The systems modeling approach identifies features as the primary components of value provided by the designed system. Applying the approach, students develop lists of stakeholders and features followed by a map that identified which stakeholders valued which features. While this stakeholder model was effective at helping students to identify stakeholders and think about what they valued, its simplicity left hidden some important aspects of the associations between stakeholders and features. This paper develops a clearer connection between features, stakeholders, and value provided with two proposed model views. The first proposed view identifies all relevant stakeholders in the value chain and indicates desirable features for each stakeholder group with degree of value placed on each one. The second view provides a structure to compare candidate designs through their level of attainment of the key features identified.

These modified views will be compared against existing design approaches typically used and taught in the classroom and other alternatives to illustrate the benefits that this new approach offers, which includes a more comprehensive approach for identifying multiple stakeholders and their needs and the ability to focus student attention on multiple perspectives of 'creating value', including financial, social, and environmental. This also includes defending existing value, when it is threatened by potential innovations improving other areas. These two new views are illustrated through a design case study for a remote control device.

\section{Literature Review}

In a paper reviewing the design education literature, Dym et al. note, "design is hard to learn and harder still to teach” (Dym et al., 2005). Supporting this assessment, some 40 percent of new 
products fail to find success in the marketplace (Castellion and Markham, 2013). The consideration of 'features' has been identified as an important aspect of product success. Ulwick proposes that new product success is most often correlated with a "need first" approach that first explores stakeholder needs and desired features rather than an "idea first" or creativity driven approach (Ulwick, 2011). Crismond and Adams compare the traits of student designers compared to more experienced designers and conclude that students a. don't collect enough or the right information before they start designing and b. make design decisions without properly considering all options (Crismond and Adams, 2012). In addition, when designing new products it is important to include features to retain current customers as well as attract new customers (Hamilton et al., 2017). Lastly, consumers often believe that they want a product that is loaded with features but later may be overwhelmed by the product's complexity (Rust et al., 2006). It becomes clear that a sharper focus on stakeholders and features is a critical requirement for product success and an integrated approach is needed to help students navigate these complexities.

A systems engineering approach for undergraduate design education has been applied in first year to capstone design courses to help students with designing systems (Simoni, et al., 2016). The advantages of the approach are that one set of models or views is applicable to a wide variety of design problems making the common approach easier for students to learn and faculty to teach and assess. As part of this approach, students must start by determining the relevant stakeholders and features of a design. To help with assessment, a set of rubrics were developed and provided to the students to ensure they aren't missing, for instance, a common stakeholder and/or feature. In addition, these rubrics provide helpful guidance because every stakeholder must have at least one feature and all features should have at least one stakeholder. By having these models, faculty can assess and provide feedback much more quickly. It takes much less time to review model drawings and views rather than pages of prose to determine if students have missed stakeholders, have missing or extra features, and have captured the interrelations between the two.

\section{Objectives of this Study}

Several objectives were identified at the outset of this work. A general objective is to develop design education approaches based on systems engineering principles that focus on creating and defending value to help to address the poor rate of success as noted above.

Another objective of the work is to introduce two detailed views: one to encourage students to identify relevant stakeholders and collect the right information to frame a problem, and the other to encourage students to make design decisions or selections based on a thoughtful evaluation of stakeholder features captured at the start.

Another objective is to highlight the multiple dimensions of value including technical, financial, environmental, and health/safety. Often, value is only considered in terms of financial gains; however, great companies also consider other measures of success by "invest(ing) in the future while being aware of the need to build people and society.” (Kanter, 2011) 
Another objective of the work is to highlight that "creating value" and value itself is not a property of the system being designed but rather it is determined in how stakeholders view the system and ultimately select it or an alternative. Without identifying all relevant stakeholders and understanding their desired features and priorities, the resulting gaps and misalignments can result in product failure.

\section{Systems Engineering Based Design Approach}

In a previous paper, a model-based approach for teaching undergraduates system engineering principles through multiple views has been developed. These views included a stakeholder feature model, interactions model, functional architecture, technical requirements, and physical architecture (Simoni et al., 2016). The purpose of having multiple views is to ensure complete representation of the necessary aspects (behavior, value, and design) of the system (Schindel, 2011). Figure 1 shows a Functional Architecture diagram and Figure 2 shows a Stakeholder/ Feature view from a collection of views for a TV remote control (Simoni et al., 2016). The functional architecture view shows interactions with external systems or actors and also the internal functions that support the input/output behavior of the system.

The stakeholder/feature view in Figure 2 encourages students to identify relevant stakeholders other than simply the final user of the device. Common stakeholders often include the customer, buyer, servicer, regulatory agencies, manufacturers, and retailers. Often students will only think about the product in terms of the user but other stakeholder groups can have an impact on the success or failure of the final design. In addition, this view provides the student with the necessary framework to think about all possible features that stakeholders might value. Thinking from these different stakeholder perspectives helps students be able to think about the connections between stakeholders and features and missed features, unnecessary features, or features that may be in conflict with other ones. For instance, for a TV remote, students might forget the importance of testability during the manufacturing stage of the design or fail to notice possible conflict between features such as durability and recyclability. Key shortcomings with the stakeholder feature view in Figure 2 are that it does not capture the degree to which a certain feature is valued by a particular stakeholder nor does it capture feature attributes or the quantitative metrics necessary to more fully describe the feature. In reality, different stakeholders value features at varying levels with some features valued positively by some stakeholders and negatively by others.

New Views for Stakeholders, Features, and Value Creation

As noted above, several key elements in design success include - identification of relevant stakeholders via sponsors and patterns, identification of important features and attributes, and ensuring that final design that is selected provides the envisioned features and value above existing alternatives.

A proposed view for stakeholders and features for the remote control example is presented in Figure 3. This view encourages students to identify relevant stakeholders, features of importance, feature attributes (possibly multiple ones per feature), and the completeness and alignment between the two. A key shortcoming with the previous stakeholder feature model is 
that it does not capture the degree to which a feature is valued by a particular stakeholder. It only denotes whether or not there is a connection/association between a feature and stakeholder when in reality, certain stakeholders value features at varying levels with some features valued positively by some stakeholders and negatively by others.

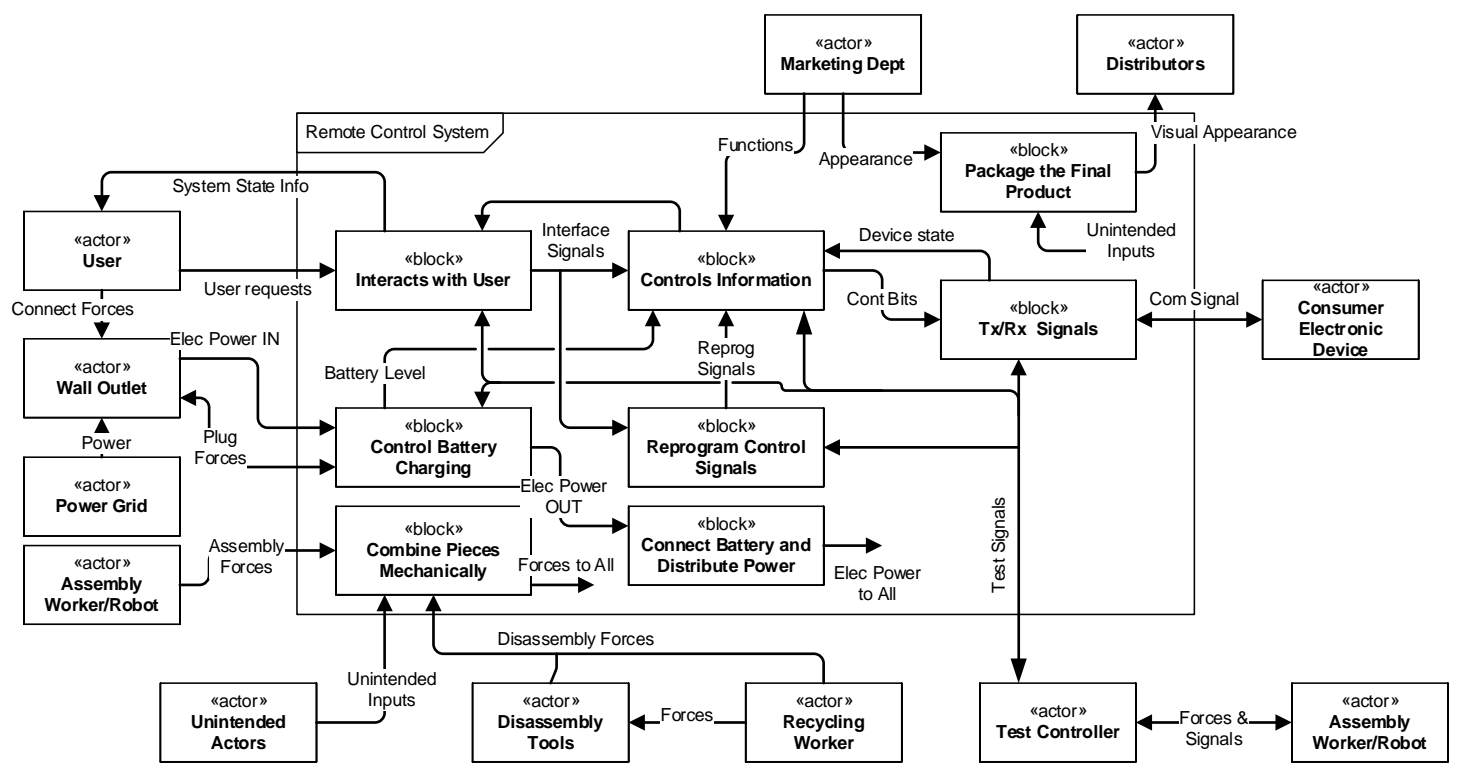

Figure 1 - Functional Architecture for Remote Control from Simoni et al., 2016

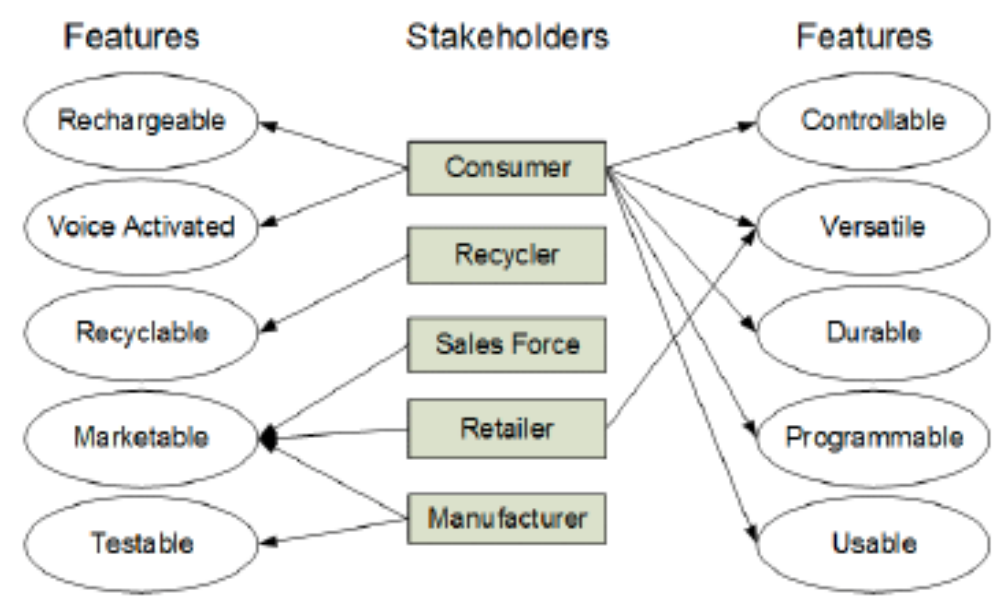

Figure 2 - Stakeholder / Feature view from Simoni et al., 2016

\section{Stakeholder / Feature View}

The proposed Stakeholder/Feature view in Figure 3 is proposed to provide an expanded look at the relationship between stakeholders and features. This view identifies multiple relevant 
stakeholders, desired features, feature attributes, and the value of each feature. Each stakeholder may value features differently (expected, delighter, one dimensional, dissatisfiers, and don't care) (Kano et al., 1984). Feature attributes provide more detail by identifying quantifiable metrics that enable evaluation of final designs to determine attainment of features.

\begin{tabular}{|c|c|c|c|c|}
\hline & & \multicolumn{3}{|c|}{ Stakeholders from User to Provider } \\
\hline & & User & Buyer & Manufacturer \\
\hline & Stakeholder Priority & High & High & Moderate \\
\hline Feature Name & Feature Attribute & Feature Priority & Feature Priority & Feature Priority \\
\hline Controllable & Number devices controlled & $\mathrm{E} / 1$ & & \\
\hline Versatile & Number features controlled & $E / 1$ & & \\
\hline & & & & \\
\hline Durable & Shock resistance & $\mathrm{E}$ & & \\
\hline & Water resistance & $E$ & & \\
\hline & & & & \\
\hline Programmable & Number devices controlled & $E$ & $E$ & \\
\hline Rechargeable & Recharge time & $\mathrm{D}$ & & - \\
\hline Voice Activated & Number of Commands & $\mathrm{D}$ & & - \\
\hline & & & & \\
\hline Affordable & Price & & $E / D$ & $\mathrm{E}$ \\
\hline Manufacturable & Number of parts & & & $E$ \\
\hline & Mfg Cost & & & $\mathrm{E}$ \\
\hline & $E=$ Expected, $D=$ & 1-1 Dimensir & lont) & \\
\hline
\end{tabular}

Figure 3 - Stakeholder / Feature View for Remote Control Example

For the remote control example, three key stakeholders are shown: user, buyer, and manufacturer. In many situations, the user and the buyer are different people and have different features and priorities. Figure 3 shows that most of the remote control features are of interest to the user with a price conscious buyer being primarily interested in affordability and price. The features of interest to the user are of little interest to the manufacturer who may be more interested in manufacturing cost and number of parts in the device.

\section{Features / Designs View}

The proposed Feature/Design view in Figure 4 is proposed to aid in the selection of a final design using the same features from Figure 3. During the design process, multiple candidate designs are often generated and each may do a better or worse job of attaining desirable features. This selection process is often accomplished by a separate selection committee using a decision matrix with the same or different set of criteria (Ulrich and Eppinger, 2011). During this process, candidate designs are also often compared to a benchmark.

Figure 4 shows that three candidate designs have been proposed: a basic, intermediate, and premium design. The same set of features used in Figure 3 are again used here to aid in selection of a final design. Each design is evaluated by their relative attainment of the features and attributes. Design 1 (D1) is selected as the benchmark and the other two designs compared to 
this one. For the voice activated feature, D3 attains this feature to a higher degree (0.8) than D1 and D2 (0.0). As is often the case in consumer products, this example illustrates that more features often come at a lower level of affordability. These comparative design alternative (Dn) columns can also be used to compare to competitor existing or projected designs, or other benchmark configurations in which comparative value is of interest.
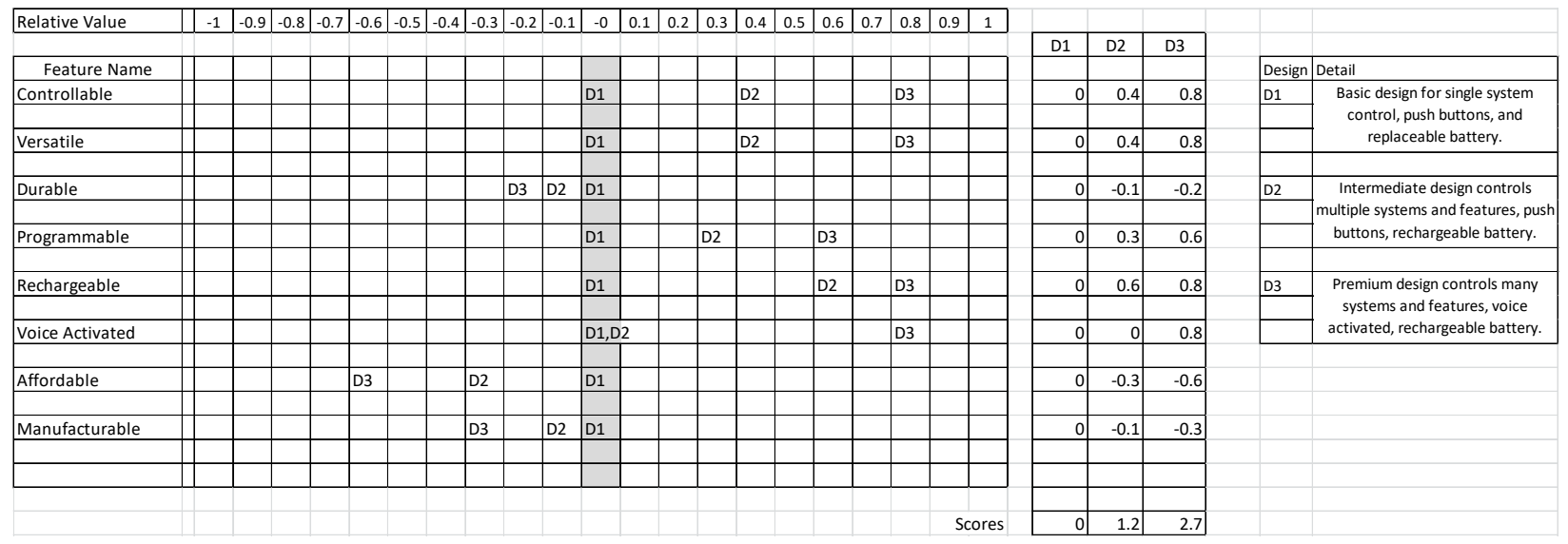

Figure 4 - Feature / Design View for Remote Control Example

\section{Proposed views vs. Existing approaches}

Design is often taught in undergraduate design courses as a process with a common approach similar to what is described Ulrich and Eppinger (Ulrich and Eppinger, 2011). A common method of capturing customer needs is a "Needs/Metrics Matrix". Needs are often vague expressions of desirable product characteristics and metrics are the needs translated into quantifiable measures. There are variations on this widely used approach. The main drawback to this approach is that it collects needs mainly from the "customer" and if needs come from multiple stakeholders, this information is often lost. In the proposed view in Figure 3, needs correspond to features and metrics correspond to feature attributes. Figure 3 provides the advantage of clearly identifying multiple stakeholders with connection to their expressed features.

In the later stages of the design process when multiple concept designs have been created, a concept scoring or weighted decision matrix is commonly used to select a final design from the candidates. (Ulrich and Eppinger, 2011). A variety of team based methods are used in this step often comparing to a benchmark. The view in Figure 4 proposes using the same features collected in the stakeholder/feature view in this selection process. Figure 4 compares multiple candidate designs to a benchmark on a relative scale of how well the design attains each of the features. Candidates that exceed the benchmark in feature attainment show up on the right side of the view with positive scores. The graphical view also makes it clear when a candidate design performs poorly in feature attainment because it appears on the left side of the view. 
The Feature/Design view can also be used early in the design process in a benchmarking exercise. After stakeholders and features are identified, it is often suggested to do a benchmarking study of existing products. The Feature/Design view can also be used to score and compare existing products and solutions and their relative attainment of the key features.

Stakeholders and Features for Technical, Financial, and Contemporary Design Objectives An advantage of the proposed Stakeholder/Feature view is the ability to include a range of design objectives such as technical, financial, social, and environmental in the design approach. Several of these features are critical to meeting ABET criteria for student outcomes (ABET, 2015). Table 1 below shows the suggested category of objective and possible features and feature attributes that could be included in the Stakeholder/Feature table. For example, students could include the 'environmentally friendly' feature in their design with feature attributes of 'volume of production waste' and 'percent recyclable materials'. Using this approach, these contemporary design objectives can be directly integrated into the design problem.

Advantages of proposed views over existing approaches

Summarizing the previous discussion, the proposed views offer several advantages over existing approaches:

- The views seamlessly tie into the successful design approach described in the previous paper (Simoni et al., 2016),

- The views provide direct connection to failure modes and effects analysis (FMEA) and risk management,

- The Stakeholder/Feature view encourages explicit identification of multiple stakeholders, while current approaches focus mainly on a 'customer' or the final user,

- The Stakeholder/Feature view encourages the identification of a range of traditional, competitive, and contemporary design priorities and features that are valued by stakeholders - the contemporary items include environmental, social, and sustainable design priorities,

- The Feature/Design view clearly identify comparative feature attainment for multiple candidate designs,

- The views use the same feature set for both designing the system and selecting a final design from a set of candidates.

Future Work

Several future activities are planned to continue this work. These views will be incorporated within capstone design courses that have currently adopted the approach outlined in Simoni et al. This will provide an opportunity to gauge their effectiveness at improving design outcomes by evaluating student reports through more formal assessment studies. If improved design outcomes are noted, additional detail will be pursued on whether the improvements can be attributed to stakeholder or feature identification, some combination of the two, or other aspects of the views. Complementary activities include the offering of a campus seminar on 'creating value' to explore the effectiveness of these views in more general decision-making settings. 


\section{$\underline{\text { Summary and Conclusions }}$}

This paper extends previous work that introduced a model-based approach for introducing systems concepts in undergraduate design curriculum. Two views have been proposed including a Stakeholder/Feature view that encourages identification of multiple stakeholders and the identification of a range of design priorities and features that are valued by stakeholders. The Feature/Design view clearly identifies comparative feature attainment for multiple candidate designs and uses the same features for final system selection from a candidate set.

These proposed views highlight that while features are a key element in system design, the value provided by them is not intrinsic to the system itself but to its stakeholders. The "right" feature mix implies identification of the related set of stakeholders; this means that identifying the "right" set of stakeholders is critical for achieving success.

As this is a model-based approach, it is both flexible and scalable. The proposed views provide an enhanced look at stakeholders, features, and value and enable students and instructors to more clearly identify gaps and misalignments that may lead to unsuccessful designs.

\section{References}

ABET Engineering Accreditation Commission, Criteria for Accrediting Engineering Programs, Effective for Reviews During the 2016-17 Cycle, Baltimore, MD, October 16, 2015.

Castellion, G. and Markham, S. K. (2013), "Perspective: New Product Failure Rates: Influence of Argumentum ad Populum and Self-Interest”, Journal of Product Innovation Management, 30: 976-979. doi:10.1111/j.1540-5885.2012.01009.x

Crismond, David P. and Robin S. Adams, "The Informed Design Teaching and Learning Matrix”, Journal of Engineering Education, October 2012, Vol. 101, No. 4, pp. 738-797.

Dym, Clive L., Agogino, Alice M., Eris, Ozgur, Frey, Daniel D., and Leifer, Larry J. (2005). "Engineering Design Thinking, Teaching and Learning”, Journal of Engineering Education 94(1), 103-120.

Hamilton, Rebecca W., Roland T. Rust, and Chekitan S. Dev, "Which Features Increase Customer Retention?” MIT Sloan Management Review, Winter 2017 November 30, 2016, p. 79-84.

Kano, N., Seraku, N., and Tsuji, S. (1984). “Attractive Quality and Must-Be Quality”, Proc. 12th Annual Meeting of the Japan Society of Quality Control.

Kanter, Rosabeth Moss. "How Great Companies Think Differently." Harvard Business Review 89, no. 11 (November 2011).

Kline, William A. and William D. Schindel, 'The Innovation Competencies- Implications for Educating the Engineer of the Future’, Proceedings of the 2014 ASEE Annual Conference, Indianapolis, IN, June 2014. 
Osterwalder, Alexander, and Yves Pigneur. (2010) Business Model Generation: A Handbook for Visionaries, Game Changers, and Challengers. Hoboken, NJ: Wiley.

Rust, Roland T., Debora Viana Thompson, and Rebecca W. Hamilton, "Defeating Feature Fatigue”, Harvard Business Review, February 2006, p. 39-47.

Schindel, William D. "What Is the Smallest Model of a System?" INCOSE International Symposium 21, no. 1 (2011): 99-113. doi:10.1002/j.2334-5837.2011.tb01188.x.

Schindel, William D. "Maps or Itineraries? A Systems Engineering Insight from Ancient Navigators,” INCOSE 2014 Great Lakes Regional Conference on Systems Engineering, Chicago, 2014.

Simoni, Mario, Eva Andrijcic, Bill Kline, and Ashley Bernal, "Helping Undergraduate Students of any Engineering Discipline Develop a Systems Perspective”, 26th Annual INCOSE International Symposium (IS 2016), Edinburg, Scotland, UK, July 18-21, 2016.

Ulrich, K. T., and S.D. Eppinger (2011). Product Design and Development, $5^{\text {th }}$ Edition, McGraw-Hill Education.

Ulwick, Anthony W. "What is Outcome Driven Innovation (ODI)?” Strategyn Whitepaper. 2011. 


\begin{tabular}{|c|c|c|}
\hline Category & Possible Features & Possible Attributes \\
\hline Financial & Affordable, Profitable & Cost, Revenue, Profit, Capital, ROI \\
\hline Marketing & Marketable & $\begin{array}{l}\text { Number of Sales Channels, } \\
\text { Customer Segments, Market Share }\end{array}$ \\
\hline Environmental & Environmentally Friendly & $\begin{array}{l}\text { Amount of Production Waste, } \\
\text { Local Production (i.e. \% of good } \\
\text { sourced within a certain mileage), } \\
\text { Percentage of Recyclable Materials }\end{array}$ \\
\hline Social & $\begin{array}{l}\text { Economic Development, } \\
\text { Quality of Life }\end{array}$ & $\begin{array}{l}\text { Job Creation, } \\
\text { Access to Resources (water, energy, } \\
\text { food), } \\
\text { Access to Health Care, } \\
\text { Safety (crimes per } 1000 \text { residents) }\end{array}$ \\
\hline Political & $\begin{array}{l}\text { Political Priorities, } \\
\text { Regulations }\end{array}$ & $\begin{array}{l}\text { Industry Sector, } \\
\text { Social Cause, } \\
\text { OSHA, EPA, FCC, NHTSA }\end{array}$ \\
\hline $\begin{array}{l}\text { Ethical, } \\
\text { Health and Safety }\end{array}$ & Compliance to Standard & UL, CE, ISO, NSF, SAE \\
\hline Manufacturability & Manufacturable & $\begin{array}{l}\text { Manufacturing cost, } \\
\text { Number of Operations, } \\
\text { Part Count, } \\
\text { Assembly Time, Yield }\end{array}$ \\
\hline Sustainability & Sustainable & $\begin{array}{l}\text { Carbon Content \%, } \\
\text { Amount of Recyclable Materials }\end{array}$ \\
\hline
\end{tabular}

Table 1 - Suggested Features and Attributes for a Variety of Student Outcomes 